\title{
EFFECT OF FEED RATE ON SURFACE INTEGRITY AND TOOL WEAR DURING SHORT TURNING OF AISI 1045 CARBON STEEL
}

\section{NORFAUZI TAMIN ${ }^{1}$, MOHD HADZLEY ABU BAKAR ${ }^{1 *}$, UMAR AL AMANI AZLAN ${ }^{1}$, MOHD FAIRUZ RASHID $^{2} \&$ SAFARUDIN GAZALI HERAWAN ${ }^{3}$}

${ }^{1}$ Faculty of Mechanical and Manufacturing Engineering Technology, Universiti Teknikal Malaysia Melaka, Hang Tuah Jaya, Durian Tunggal, Melaka, Malaysia.

${ }^{2}$ Jabatan Keselamatan dan Kesihatan Pekerjaan Melaka, Aras 3 dan 4, Menara Persekutuan, Jalan Persekutuan, Hang Tuah Jaya, Ayer Keroh, Melaka, Malaysia

${ }^{3}$ Industrial Engineering Department, Faculty of Engineering, Bina Nusantara University, Jakarta, Indonesia

\begin{abstract}
AISI 1045 medium carbon steel considered among materials that commonly used as machining product. The quality of machined surface of AISI 1045 strongly dependent on the characteristics of cutting tool and the cutting parameters. Inappropriate use of cutting parameters would lead to the accelerating tool wear and rough surface finish, which would lead to the deteriorate machining performance. This project presents of feed rate on the tool wear and surface roughness when turning AISI 1045 carbon steel without cutting fluid. This experiment was conducted at a short machining time using a CNC turning in dry condition with feed rates ranged from $0.15 \mathrm{~mm} / \mathrm{rev}$ to $0.5 \mathrm{~mm} / \mathrm{rev}$, cutting speeds ranged from $35 \mathrm{~m} / \mathrm{min}$ to $53 \mathrm{~m} / \mathrm{min}$ and depth of cut constant at $1 \mathrm{~mm}$. The results show that at the low feed rate of $0.15 \mathrm{~mm} / \mathrm{rev}$, the surface roughness demonstrated uneven trend ranged from $3.8 \mu \mathrm{m}$ to $5.86 \mu \mathrm{m}$ with the tool wear recorded increased from $0.0696 \mathrm{~mm}$ to $0.1405 \mathrm{~mm}$. As the feed rate increased to $0.5 \mathrm{~mm} / \mathrm{rev}$, the surface roughness increased from $8.68 \mu \mathrm{m}$ to $17.28 \mu \mathrm{m}$ and the tool wear recorded increment from $0.0755 \mathrm{~mm}$ to $0.1810 \mathrm{~mm}$. Surface finish appeared with feed marks and material side flow while the tool wear suffered with flank wear, crater wear and chipping. This study will provide guidelines to machine AISI 1045 effectively and provide understanding the characteristics of surface finish and tool wear especially under dry condition at a short machining time.
\end{abstract}

KEYWORDS: Surface Roughness; Feed Rate; Turning; Tool Wear; Wear Mechanisms

Received: Jun 08, 2020; Accepted: Jun 28, 2020; Published: Sep 30, 2020; Paper Id.: IJMPERDJUN20201459

\section{INTRODUCTION}

Machining is a material removal process to produce the product by shearing layered of materials into required shape. During machining, cutting tool engaged with the workpiece material and applied shearing force to distort the workpiece, produce the chips and leaving surface finish at the end of process (Kalpakjian and Schmid, 2003). Among materials that commonly used as machining product including AISI 1045 mild steel. AISI 1045 is a medium carbon steel that contained around $0.45 \%$ carbon. This steel designed for moderate forming into wrought products with fairly good strength and impact properties. This steel possesses high machinability and considered low hardenability due to its limited alloy condition. Typical tensile strength of AISI 1045 range around $530 \mathrm{MPa}$ with Rockwell hardness range around B90 (Huyett, 2004). Machining product of AISI 1045 process already established in many applications including automotive, aerospace, petroleum and machine tool industries. 
Machining often produce heat due to friction and deformation of workpiece that changed mechanical energy into heat. The existence of heat energy can benefit the process in terms of softening the primary shear zone to assist the chip deformation (Norfauzi et al., 2017). One the other hand, the existence of heat could also deteriorate machining performance as heat can accelerate wear that detrimental to the cutting tool and surface finish. Partial of the heat also can be absorbed into the workpiece, resulting several phenomena occurred such as thermal expansion, material side flow or detachment of molten particles. Even though the heat can be controlled if the coolant was used, such situation provides another drawback as coolant is hazard to the operator and environment. Especially, when machining within short time, the use of coolant maybe not necessary as the operational cost could be higher (Grover and Khan, 2014). Thus, dry cutting still preferable condition as the surface roughness still can be controlled with the manipulation of machining parameters.

In the machining process, the surface finish plays an important role as a criterion to evaluate their performance. Surface finish influences final properties of the machined parts, such as dimension accuracy, contact condition, surface friction, resistance to stress concentration, fatigue resistance, heat conductivity, light reflection and physical appearance for the end product (Faiz et a., 2019). In general, surface roughness can be measured to evaluate the surface finish of AISI 1045. Considered the cutting tool can shear the material in ideal condition, the surface roughness strongly influence by the nose radius of cutting tool and cutting parameters, defined by the cutting speed, feed rate and depth of cut (Dogra et al., 2011). Higher cutting speed is preferable as the cutting tool can slice material cleanly to produce the surface texture according to the nose radius. However, higher cutting speed would generate heat that detrimental to the machining performance in a long time. Lower feed rate is preferable as the cutting tool can slice layers of material repetitively to eliminate small peak and crescent produced by the tool nose radius. However, too many repetitive contacts may induce early tool wear. Lower depth of cut is preferable to control layer of surface texture to be removed. However, lower depth of cut will delay the material removal process and hence increasing production time (Norfauzi et al., 2017).

Even though the usage of AISI 1045 already established in industry, the information regarding the characteristics of surface roughness when the cutting parameters changed considered still not well explored, especially in dry condition and at the short machining time. The monitoring of surface roughness requires evaluation and microscopy analysis to represent the material behaviour and contact mechanisms at the tool-workpiece interface. As focussed on this study, AISI 1045 was machined with different feed rate and cutting speed in order to monitor the surface characteristics under dry condition, within few minutes of machining time. The tool wear and wear mechanisms with perspective to the contact with workpiece material were also presented. The study at least would provide understanding and guideline for machinist to machine AISI 1045 effectively for small and simple parts.

\section{METHODOLOGY}

\subsection{Material and Cutting Tool Preparation}

This study was conducted to identify the ability of carbide cutting tool on dry cutting and to investigate surface integrity and tool wear as a result of feed rate used. Raw materials AISI 1045 was selected based on the ability of these raw materials to produce products such as mould pins and automotive components for manufacturing production. Table 1 shows the chemical composition and mechanical properties of AISI 1045.

Table 1: Characteristics of AISI 1045 steel

\begin{tabular}{|c|c|c|c|c|c|c|c|}
\hline \multicolumn{2}{|c|}{ Chemical (\%) } \\
\hline $\mathrm{G}$ & $\mathrm{Si}_{\max }$ & $\mathrm{S}_{\max }$ & $\mathrm{P}_{\max }$ & $\mathrm{Mn}$ & $\mathrm{Cr}_{\max }$ & $\mathrm{CU}_{\max }$ & $\mathrm{Ni}_{\max }$ \\
\hline
\end{tabular}




\begin{tabular}{|c|c|c|c|c|c|c|c|}
\hline $0.42-0.5$ & 0.4 & 0.045 & 0.04 & $0.5-0.8$ & 0.3 & 0.3 & 0.4 \\
\hline \multicolumn{7}{|c|}{ Mechanical characteristics } \\
\hline $\mathrm{R}_{\mathrm{e}}[\mathrm{Mpa}]$ & & $\mathrm{R}_{\mathrm{m}}[\mathrm{Mpa}]$ & & As $(\%)$ & & & HB \\
\hline 305 & & 580 & & 16 & & & 250 \\
\hline
\end{tabular}

This material being machined with ZP352 TNMG 160404-MB Sandvik Coromant carbide insert, as shown in Fig. 1(a). The inserts were clamped using tool holder as shown in Fig. 1(b). Two types of instruments, a surface roughness tester (Mitutoyo Surftest SJ-410) and an optical microscope (Nikon Measuring Microscope MM-800), were used to measure the surface roughness and tool wear of the AISI 1045 carbon steel. The evaluation of tool wear was conducted according to ISO 3685 where the distance of wear length was measured using measurement software that interfaced with microscope. Further analysis of surface profile and wear behaviour was conducted by using Scanning Electron Microscope (SEM).

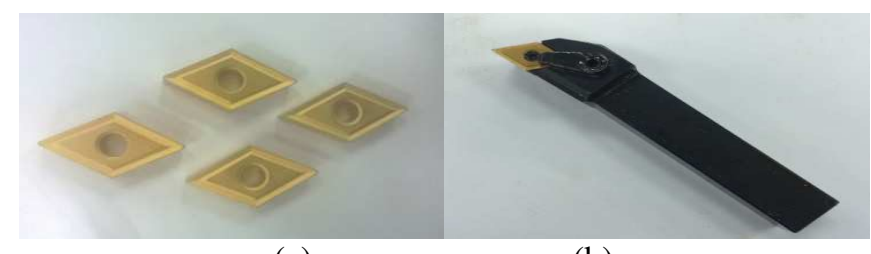

(a)

(b)

Figure 1: (a) Carbide insert type DNMG 150404-V (b) Insert holder

\subsection{Machining Process}

Machining tests were performed by using a computer numerical control (CNC) turning machine HAAS S1-20 brand with various feed rates and cutting speeds at depth of cut (DOC) at a constant state of 1.0mm. Fig. 2 shows the CNC machine and the turning process can be seen in Table 2 with eight test runs. All machining tests were run at short machining time within the length around $250 \mathrm{~mm}$ of steel bar.

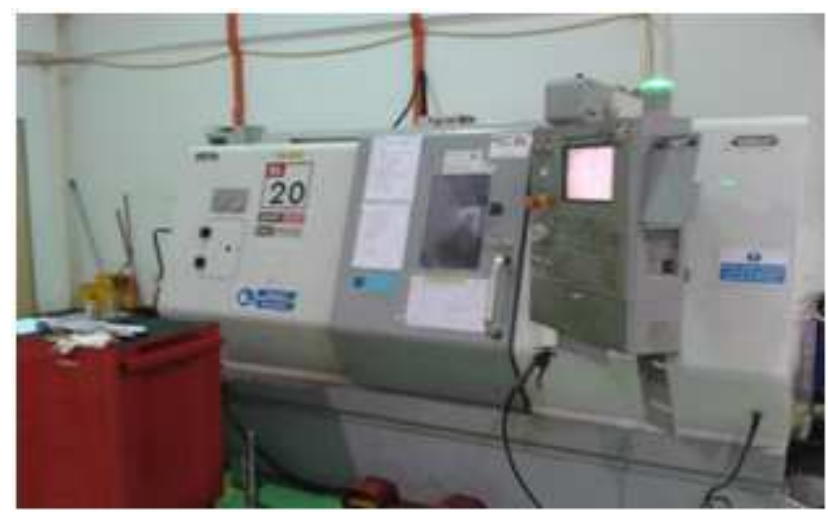

Figure 2: CNC Lathe machine

Table 2: Dry cutting process variables

\begin{tabular}{|c|c|c|c|}
\hline Test run & $\begin{array}{c}\text { Cutting } \\
\text { speed } \\
(\mathbf{m} / \mathbf{m i n})\end{array}$ & $\begin{array}{c}\text { Feed rate } \\
(\mathbf{m m} / \mathbf{r e v})\end{array}$ & $\begin{array}{c}\text { Depth of cut } \\
\text { (mm) }\end{array}$ \\
\hline 1 & 35 & & \\
\hline 2 & 41 & \multirow{2}{*}{0.15} & \multirow{2}{*}{1} \\
\hline 3 & 47 & & \\
\hline 4 & 53 & & \\
\hline 5 & 35 & & \\
\hline 6 & 41 & & \\
\hline
\end{tabular}




\begin{tabular}{|l|l|l|l|}
\hline 7 & 47 & 0.50 & 1 \\
\hline 8 & 53 & & \\
\hline
\end{tabular}

\subsection{Measurement}

Flank wear measurement test was performed by using a microscope tool maker as shown in Fig. 3 and wear rate of $0.3 \mathrm{~mm}$ conducted according to ISO 3685 standard on each cutting tool (Norfauzi et al., 2019). Measurement was made periodically according to the cutting length of workpiece bars and the image was captured by using a digital camera each of measurement.

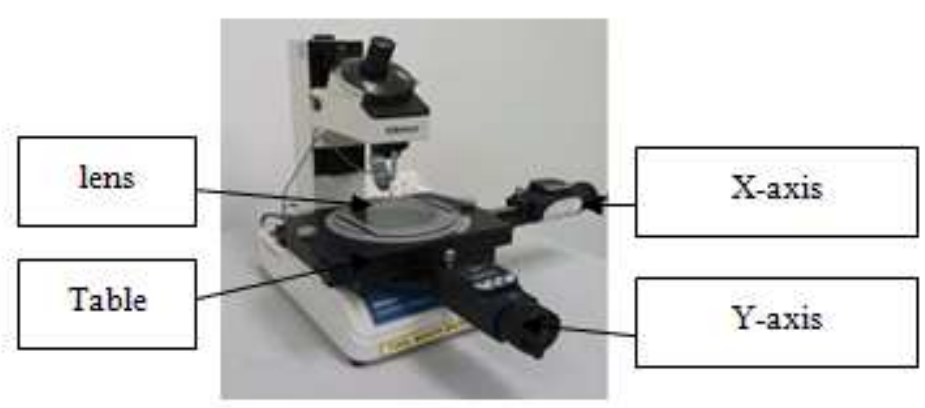

Figure 3: Toolmaker microscope

\section{RESULTS AND DISCUSSIONS}

\subsection{Surface Roughness Measurement}

Fig. 4 shows the effect of cutting speed on surface roughness for $0.15 \mathrm{~mm} / \mathrm{rev}$ feed rate (Fig. $4(\mathrm{a})$ ) and $0.5 \mathrm{~mm} / \mathrm{rev}$ feed rate (Fig. 4(b)). By using $0.15 \mathrm{~mm} / \mathrm{rev}$ feed rate, the surface roughness values demonstrated an increasing trend from cutting speed of $35 \mathrm{~m} / \mathrm{mon}$ to $47 \mathrm{~m} / \mathrm{min}$ with value from $3.803 \mu \mathrm{m}$ to $5.861 \mu \mathrm{m}$. However, when cutting speed increased to $53 \mathrm{~m} / \mathrm{min}$, the surface roughness value decreased to approximately $4.063 \mu \mathrm{m}$. By using $0.50 \mathrm{~mm} / \mathrm{rev}$ feed rate, a remarkable increase in the surface roughness was recorded when the cutting speed increased from $35 \mathrm{~m} / \mathrm{min}$ to $53 \mathrm{~m} / \mathrm{min}$ where the surface roughness increased tremendously from $11.385 \mu \mathrm{m}$ to $17.35 \mu \mathrm{m}$. At higher feed rate, the transverse movement of tool nose radius remarking larger feed marks, increasing the gap between peak to peak values, resulting higher surface roughness (Norfauzi et al., 2017). Based on the findings shown in Fig. 4(a) and (b), the surface roughness when machining AISI 1045 carbon steel generally increased with increasing cutting speed. In term of feed rate, the machining demonstrated obvious increment of surface roughness when then feed rate increased, particularly from 0.15 to $0.50 \mathrm{~mm} / \mathrm{rev}$. 


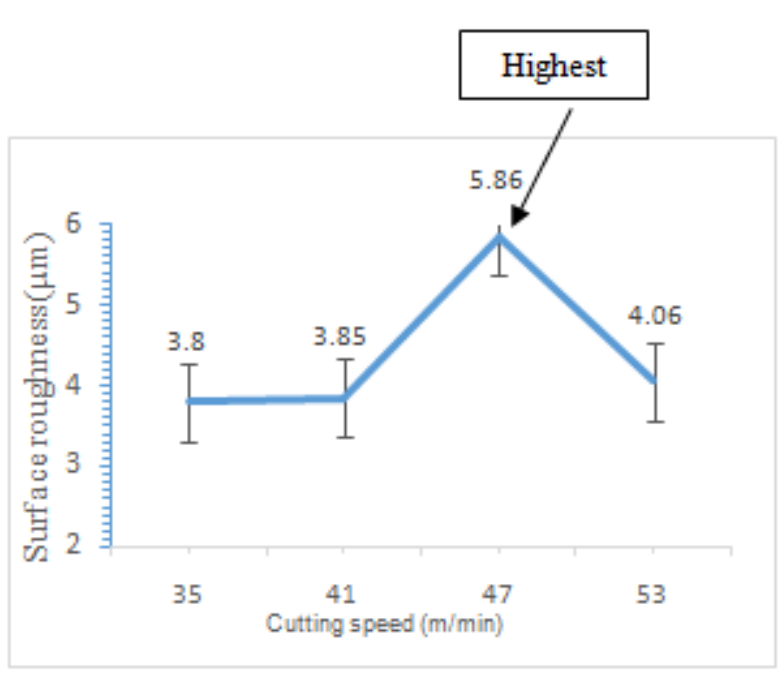

(a)

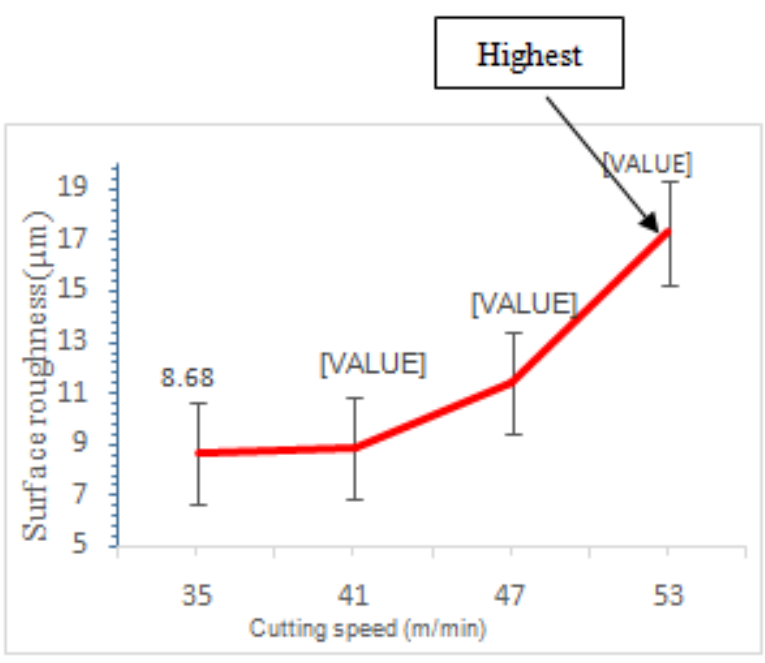

(b)

Figure 4: Result of surface roughness when machine at federate of (a) $0.15 \mathrm{~mm} / \mathrm{rev}$ and, (b) $0.50 \mathrm{~mm} / \mathrm{rev}$

Fig. 5 shows the surface profile when machining AISI 1045 under various cutting speed and $0.15 \mathrm{~mm} / \mathrm{rev}$ feed rate. Based on general observation found that some surface profile part formed a valley with significant smearing and produced a uniform peak at cutting speed $35 \mathrm{~m} / \mathrm{min}$. However, there are no visible feed mark and without the formation of side flow material which in turn reflects a smooth and shiny surface along the surface of AISI 1045. Feed mark have a significant effect in increased of the surface roughness on AISI 1045 (Hadzley et al., 2019). Based on observations show that the valley has no effect in producing smooth and shining surface of AISI 1045 and subsequently produce results as seen in Fig. 5(a) shows the surface roughness at the cutting speed of $35 \mathrm{~m} / \mathrm{min}$ is the lowest surface roughness result compared others. At the cutting speed increased to $53 \mathrm{~m} / \mathrm{min}$, the feed mark on the surface profile is clearly visible throughout the machining process and it is in line with the surface roughness results which are higher roughness than 35 $\mathrm{m} / \mathrm{min}$. The condition may be due to the end of the cutting tool getting worn out and uneven shearing as a result of repeated machining resulting from the uniformed nose radius (Norfauzi et al., 2019).

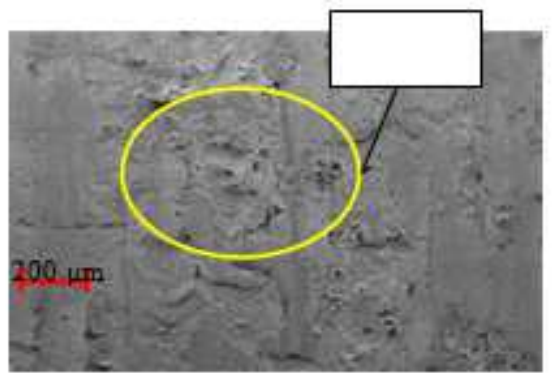

(a)

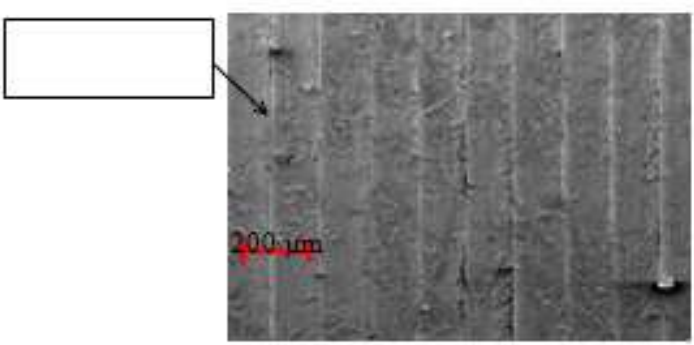

(b)

Figure 5: Surface profile at cutting speed of (a) $35 \mathrm{~m} / \mathrm{min}$ and feed rate of $0.15 \mathrm{~mm} / \mathrm{rev}$ and,

(b) $53 \mathrm{~m} / \mathrm{min}$ and feed rate of $0.15 \mathrm{~mm} / \mathrm{rev}$

Fig. 6 shows the surface profile when machining AISI 1045 under various cutting speed at $0.5 \mathrm{~mm} / \mathrm{rev}$ feed rate. Observations carried out found that the feed mark displayed was very smooth and fine at the beginning of machining and subsequently the surface roughness of the AISI 1045 deteriorated at the cutting speed of $35 \mathrm{~m} / \mathrm{min}$ and at the feed rate used 
$0.50 \mathrm{~mm} / \mathrm{rev}$. This phenomenon is due to the occurrence of worn region at the end of the cutting tool which in turn produces friction between the cutting tool and AISI 1045 during the machining process. Feed rate increased to $0.50 \mathrm{~mm} /$ rev found evidence of material side flow as shown in Fig. 6(b). This indicated that higher feed rate induced material pushing effect to the side from the feed mark parallel ridge. The particle of AISI 1045 pulled out during machining then scratched on the surface and the particle are placed overlapping which causes the surface roughness to increase significantly and indirectly causes the tool life of the cutting tool to be short.

At higher cutting speed and feed rate condition, high repetitive movements between the ends of the cutting tool and the workpiece will generate high temperatures due to friction and contact (Liu and Ai, 2004). During machining, high temperature generation that induced from materials sliding resulting softened effect to the machined surface. When the cutting tool feed aside from the shearing zone, the soft surface would plasticized to the side of feed marks, resulting material side flow appeared on the ridge (Tomkiewicz, 2011) and according to Bakar et al. (2018) stated, During machining, the material side flow occurred when the sheared workpiece materials plasticised as the results of high cutting temperature and on the same time the cutting tool push aside that material to form a deformed layer. Such material side flow would increase the risk of fatigue failure if the workpiece being used in rotating application.

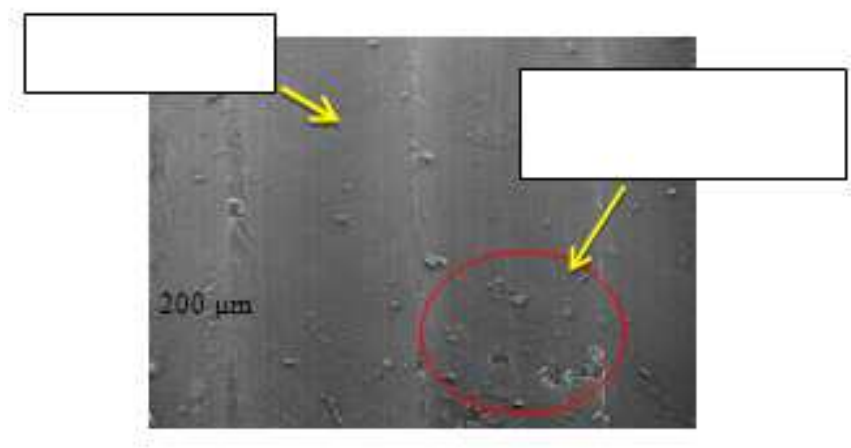

(a)

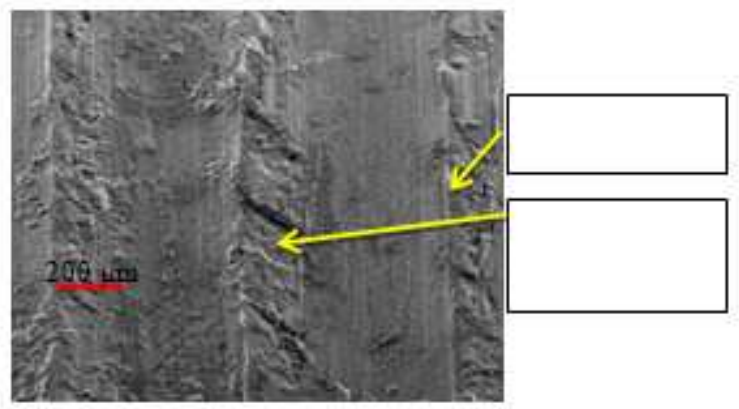

(b)

Figure 6: Surface profile for (a) cutting speed $35 \mathrm{~m} / \mathrm{min}$ and feed rate of $0.50 \mathrm{~mm} / \mathrm{rev}$ and, (b) cutting speed of 53 $\mathrm{m} / \mathrm{min}$ and feed rate of $0.50 \mathrm{~mm} / \mathrm{rev}$

\subsection{Tool Wear}

Fig. 7 shows the tool wear graphs of cutting speeds at different feed rates of 0.15 and $0.50 \mathrm{~mm} / \mathrm{rev}$. In Fig. 7(a), it can be seen at the tool wear values were $0.0696 \mathrm{~mm}, 0.0879 \mathrm{~mm}, 0.1051 \mathrm{~mm}$ and $0.1405 \mathrm{~mm}$ for cutting speeds of $35,41,47$ and $53 \mathrm{~m} / \mathrm{min}$ respectively. The values of tool wear gradually increased with the cutting speed increase from 35 to $53 \mathrm{~m} / \mathrm{min}$, namely increased up to $50.46 \%$, that's mean the surface roughness value from $0.0696 \mathrm{~mm}$ to $0.1405 \mathrm{~mm}$. The line graph shows that the value for tool wear increased as the cutting speed increased when the feed rate was at $0.15 \mathrm{~mm} / \mathrm{rev}$. Fig. 7(b) shows the values for tool wear increased with an increase in cutting speed from 35 up to $53 \mathrm{~m} / \mathrm{min}$, namely $34.75 \%$ (from $0.0755 \mathrm{~mm}$ to $0.1157 \mathrm{~mm}$ ). The line graph shows that the highest value of tool wear was $0.1157 \mathrm{~mm}$ at cutting speed of 53 $\mathrm{m} / \mathrm{min}$ while the lowest value of tool wear was $0.0755 \mathrm{~mm}$ at cutting speed of $35 \mathrm{~m} / \mathrm{min}$. At a feed rate increased to 0.50 $\mathrm{mm} / \mathrm{rev}$, the value of tool wear also increased as the cutting speed increased. 


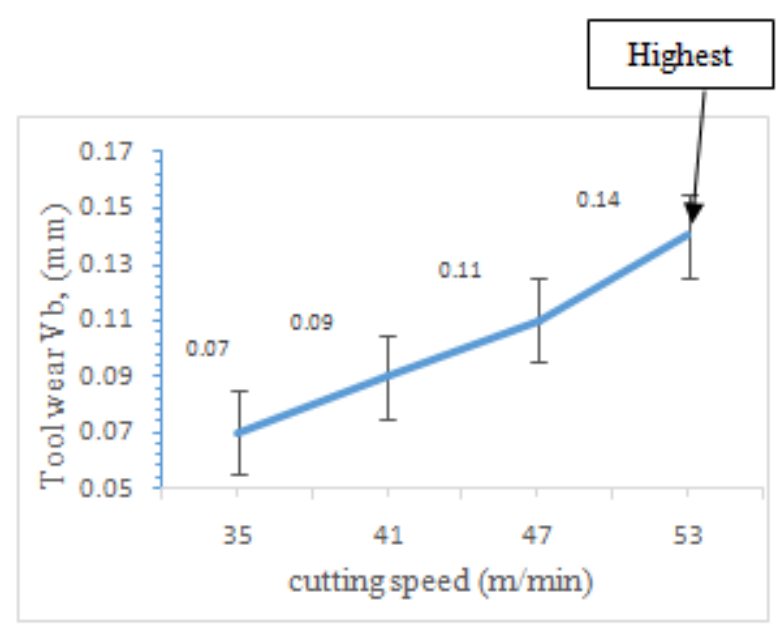

(a)

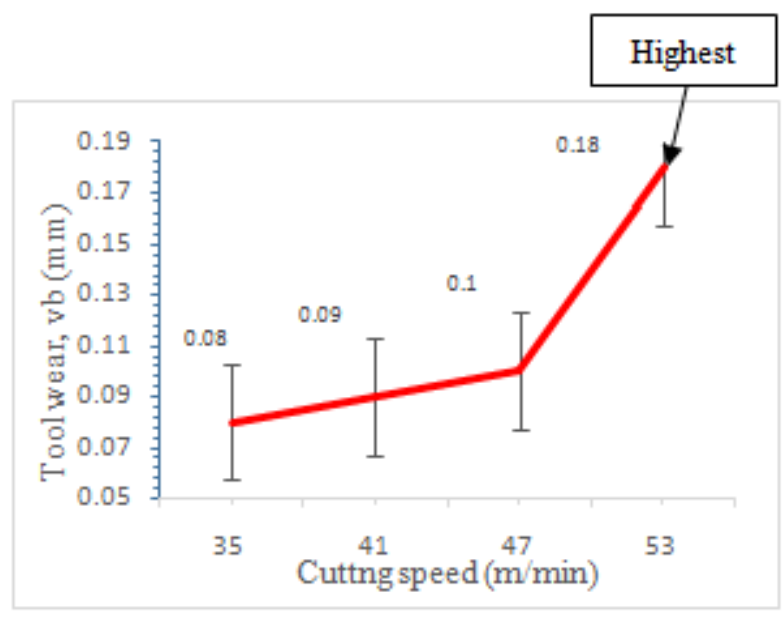

(b)

Figure 7: Effect of cutting speed on tool wear at feed rate of (a) $0.15 \mathrm{~mm} / \mathrm{rev}$ and (b) $0.50 \mathrm{~mm} / \mathrm{rev}$

Fig. 8 (a) shows the types of tool wear that visible on the carbide cutting tool when used feed rate of $0.15 \mathrm{~mm} / \mathrm{rev}$. The image shows that material gradual lost at the contact interface to represent flank and crater wears. These types of tool wear considered common in machining studies (Tomkiewicz, 2011 and Bakar et al., 2018). During tool-workpiece engagements, the initial contact of cutting tool would shear the metals and produce the surface according to the nose radius of cutting tool. As the machining progressed, the sliding and friction at the tool-workpiece interface would generate higher temperature. Some portion of cutting tool would gradually lose resulting uneven nose radius shape of cutting edge. Further machining progress would invoke small vibration and fracture at the edge of cutting tool. At the low feed rate, repetitive contact between cutting tool and workpiece would generate shear friction, resulting more material lost at the cutting edge (Alabdullah et al., 2016).

Severe of cutting edge can be classified as seen in Fig. 8(b) when using feed rate of $0.50 \mathrm{~mm} / \mathrm{rev}$. There are evidence of chipping appeared at the cutting edge. Chipping may occur due to heavy collision during initial tool-workpiece contact that break small portion of cutting tool. In addition, machining without the aid of cutting fluid with insuitablity of cutting parameters is one of the factors in the occurrence of chipping. Since the cutting tool used in this study has small nose radius of $0.4 \mathrm{~mm}$, the impact force from the rotational workpiece could induced high pressure that easily break away the tool edge. In addition, chipping also might occur as a result of material gradual lost that partially alter the tool nose radius. Assisted by the high bending feed force and temperature, small portion of material may detach from the tool edge due to unstable structural integrity at the contact zone (Bakar et al., 2018). Since the edge of cutting tool not in completed shape, chipping may destroy to surface finish by inherent shearing of workpiece with ununiformed edge.
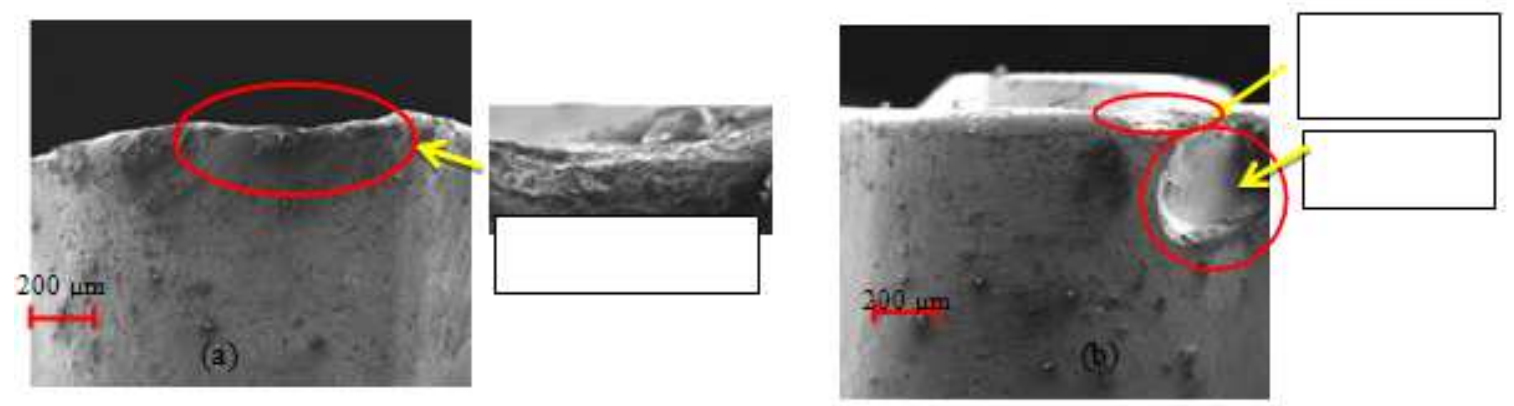

Figure 8: Wear formation when used cutting speed of $53 \mathrm{~m} / \mathrm{min}$ and federate of (a) $0.15 \mathrm{~mm} / \mathrm{rev}$ and, (b) $0.5 \mathrm{~mm} / \mathrm{rev}$ 
Crater wear has become one of the failure modes that is often become a concern by researchers (Azhar et al., 2020, Norfauzi et al., 2018 and Kasim et al., 2013). Fig. 9 clearly shows the crater wear formed on the cutting edge of the carbide cutting tool after machining carried out in dry conditions. This is due to the continuous contact of the cutting tool against AISI 1045 which subsequently forms the chip generated from the hard sliding on raw material, then the chip gradually assembles at the end of the cutting tool. It produces friction during machining operation between the cutting tool and AISI 1045 and causes generating of temperature on cutting end subsequently increase significantly. This condition causes the particles in the carbide cutting tool would be flaking and plucked off gradually, which then damages the tip of the cutting tool by producing crater wear.

At the lower feed rate of $0.15 \mathrm{~mm} / \mathrm{rev}$, the existence of crater wear demonstrated by the small area due to smaller feed force during tool-workpiece engagement, as shown in Fig. 9 (a). As the feed rate increased to $0.5 \mathrm{~mm} / \mathrm{rev}$, the crater area become larger as a result of higher feed force. Flaking occurs on the rake face specifically due to high pressure on the cutting edge (Bakar et al., 2018). In addition, the flaking phenomenon may be due to the hard-sliding chip or the friction of the chip attached to the tip of the cutting tool. The high temperature resulting from the friction produces a chip that spreads to the rake face of the cutting tool which produces diffusion wear. Diffusion wear can also cause damage to the cutting tool due to increased movement of grain structure and opening the space for chip or debris attached on the cutting edge resulting in severe damage and causing BUE as seen in Fig. 9(b).

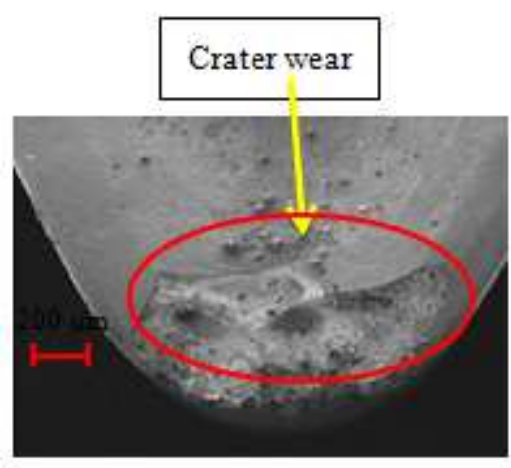

(a)
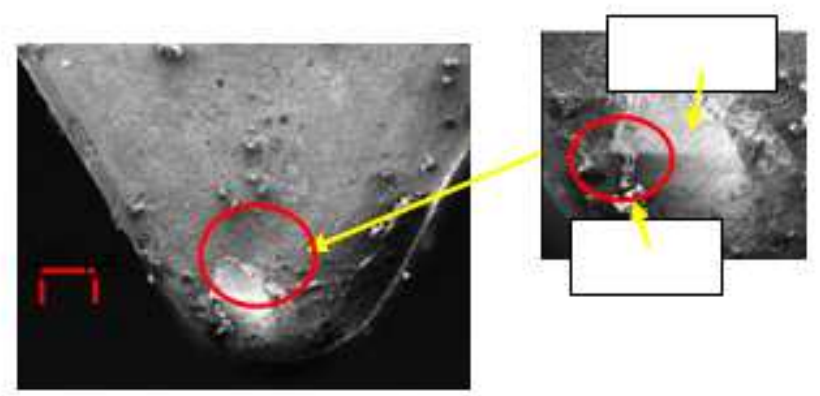

(b)

Figure 9: Formation of (a.) Crater wear and (b.) Built up edge (BUE)

\section{CONCLUSIONS}

This study was presented the effect of feed rate on the surface profile and wear of the carbide cutting tool when performing dry machining on AISI 1045. Based on the results of the study, the following shows the conclusions that can be made:

- The effect of the surface profile depends on the cutting speed and feed rate used and the suitability of both should be considered when machining on AISI 1045. Observation of surface roughness through scanning electron machine (SEM) can clearly identified the presence of feed mark when the feed rate is high.

- The increase of cutting speed give effect on surface roughness, this is due to the friction that occurs between the cutting tool and AISI $1045 \mathrm{t}$ repetitively at the cutting speed. The increase of temperature was generated has a direct effect on the contact, especially the cutting zone because it is done without using cutting fluid. While, AISI 1045 experiences a continuous deterioration of shear strength resulting in a ductile condition. 
- At cutting speeds of $35 \mathrm{~m} / \mathrm{min}$ up to $47 \mathrm{~m} / \mathrm{min}$ using the same feed rate of $0.15 \mathrm{~mm} / \mathrm{rev}$ and $0.5 \mathrm{~mm} / \mathrm{rev}$ tool wear results are equivalent. Cutting speed increased up to $53 \mathrm{~m} / \mathrm{min}$, significant wear recorded at the feed rate of $0.5 \mathrm{~mm} / \mathrm{rev}$ which increased by $50.46 \%$ compared to $0.15 \mathrm{~mm} / \mathrm{rev}$ which recorded only $34.75 \%$.

- Observation of surface profile demonstrated the appearance of feed marks, variation of peak and valley and material side flow. Observation using an optical microscope of the tool wear on the carbide insert demonstrate the appearance of flank wear, crater wear, chipping and some cracks at the tool edge.

\section{ACKNOWLEDGEMENT}

The authors would like to thank Faculty of Manufacturing Engineering and Universiti Teknikal Malaysia Melaka (UTeM) for their support that enabled this work to be carried out through the grant of FRGS /1/2017/TK03/FKP-AMC/F00341.

\section{REFERENCES}

1. Kalpakjian and Schmid. (2003). Manufacturing processes for engineering materials. Upper Saddle River, N.J: Prentice Hallm 2003.

2. Huyett. (2004). Engineering Handbook Technical Information, Industrial Press Inc, New York.

3. Anis Hor, Franck Morel, Jean Lou Lebrun, Gue na el (2013). An experimental investigation of the behaviour of steels overlarge temperature and strain rate ranges Germain. International Journal of Mechanical Sciences 67, pp. 108-122

4. A.B. Hadzley, T. Norfauzi, A.A. Umar, A.A. Afuza, M.M. Faiz and M.F. Naim, "Effect of sintering temperature on density, hardness and tool wear for alumina-zirconia cutting tool”, Journal of Mechanical Engineering Science, vol. 13, no. 1, pp. 4648-4660, 2019.

5. Grover and Khan. (2014). The Comparison on Tool Wear, Surface Finish and Geometric Accuracy When Turning EN8 Steel in Wet and Dry Conditions. Proceedings of the world congress on engineering, pp. 1093-1097.

6. Dogra, Sharmab, and Durejac. (2011). Effect of Tool Geometry Variation on Finish Turning. Journal of Engineering Science and Technology Review, 4 (1) (pp. 1-13).

7. Nishita Anandan and M. Ramulu Study of machining induced surface defects and its effect on fatigue performance of AZ91/15\%SiCp metal matrix composite, Journal of Magnesium and Alloys, Volume 8, Issue 2, June 2020, Pages 387-395

8. Liu, and Ai. (2004). High-Speed Milling of Cast Iron with Ceramic and PCBN Tools. Key Engineering Materials, (pp. 446-450).

9. Tomkiewicz. (2011). Analysis of Surface Roughness Parameters Achieved by Hard Turning with The Use of PCBN Tools. Estonian Journal of Engineering, 17 (1), (pp. 88-99).

10. Alabdullah, Polishetty, Littlefair. (2016). Impacts of Wear and Geometry Response of The Cutting Tool on Machinability of Super Austenitic Stainless Steel. International Journal of Manufacturing Engineering, 2016.

11. Okan Unal, Erfan Maleki, Ibrahim Kocabas, Haluk Yilmaz, Fazil Husem. (2019). Investigation of nanostructured surface layer of severe shot peened AISI 1045 steel via response surface methodology. Measurement, Volume 148, 106960

12. Chikalthankar.S.B, Kakade. R.B, Nandedkar.V.M, International Journal of Engineering Research \& Technology (IJERT), ISSN: 2278-0181 Vol. 3 Issue 5.2014.

13. Norfauzi, Hadzley, Azlan, Faiz, Naim and Aziz. (2018). Comparison Machining Performance of $\mathrm{Al}_{2} \mathrm{O}_{3}$, ZTA and ZTA doped $\mathrm{Cr}_{2} \mathrm{O}_{3}$ cutting tools on AISI 1045. Materials Research Express, 6 (1), 016547. 

Mohd Fairuz, Rashid \& Safarudin Gazali Herawan

14. Kasim, Haron, Ghani, Sulaiman, Yazid. (2013). Wear Mechanism and Notch Wear Location Prediction Model in Ball Nose End Milling of Inconel 718. Wear, 302 (1-2) (pp 1171-1179). 